Full-length article

\title{
Effect of cholecystokinin octapeptide on diacylglycerol-PKC signaling pathway in rat pulmonary interstitial macrophages stimulated by li- popolysaccharide ${ }^{1}$
}

\author{
Shun-jiang XU², Wei-juan GAO, Bin CONG ${ }^{3}$, Chun-ling MA, Shu-jin LI, Yi-ling LING, Zhen-yong GU, Yu-xia YAO \\ Department of Pathophysiology, Hebei Medical University, Shijiazhuang 050017, China
}

\section{Key words}

cholecystokinin; protein kinase $\mathrm{C}$; translocation; lung; macrophages; lipopolysaccharides

\footnotetext{
${ }^{1}$ Project supported by the National Natural Science Foundation of China (No 30270529) and the Natural Science Foundation of Hebei Province (No 303452).

${ }^{2}$ Now in the Hebei Province Center for Disease Prevention and Control, Shijiazhuang 050021 , China.

${ }^{3}$ Correspondence to Prof Bin CONG.

Phn/Fax 86-311-8626-5774.

E-mail bincong@263.net
}

Received 2005-03-30

Accepted 2005-08-15

doi: $10.1111 /$ j.1745-7254.2005.00217.x

\begin{abstract}
Aim: To investigate the effect of cholecystokinin octapeptide (CCK-8) on the diacylglycerol-protein kinase $\mathrm{C}$ (DAG-PKC) signaling pathway in rat pulmonary interstitial macrophages (PIM) stimulated by lipopolysaccaride (LPS). Methods: The PIM from rat lung tissues were isolated using the collagenase digestion method combined with alveolar lavage and pulmonary vessel perfusion. DAG content and PKC activity were measured by radioenzymatic assay. The translocation of PKC $\zeta$ was determined by semi-quantitative immunoblot analysis. Results: CCK- 8 , at high concentrations $\left(1 \times 10^{-6}-1 \times 10^{-5} \mathrm{~mol} / \mathrm{L}\right)$, decreased DAG content and inhibited PKC activity and $\mathrm{PKC} \zeta$ translocation compared with that in rat resting PIM of a control group $(P<0.01)$. LPS increased DAG content, and promoted PKC activity and $\mathrm{PKC} \zeta$ translocation $(P<0.01)$. CCK-8 decreased LPS-induced DAG content and inhibited LPS-induced PKC activity and PKC $\zeta$ translocation significantly at $1 \times 10^{-8}-1 \times 10^{-5} \mathrm{~mol} / \mathrm{L}(P<0.01)$. This inhibitory effect of CCK- 8 could be abrogated partly by proglumide (non-selective CCK receptor antagonist), CR-1409 (selective CCK-A receptor antagonist), and CR-2945 (selective CCK-B receptor antagonist) in a concentration-dependent manner $(P<0.01)$. Conclusion: CCK-8 was a negative modulator of the DAG-PKC signaling pathway in rat resting PIM, which is very important for maintaining body homeostasis. It significantly inhibited LPS-induced DAG content, PKC activity and PKC $\zeta$ translocation in a concentration-dependent manner. The CCK receptor, especially the CCK-A receptor, might play a major role in this process.
\end{abstract}

\section{Introduction}

Cholecystokinin (CCK) is a gut-brain peptide that exerts a variety of physiological actions in the gastrointestinal tract and central nervous system (CNS) through activating cell surface CCK receptors ${ }^{[1]}$. CCK receptors have been pharmacologically classified into 2 subtypes, CCK-A receptors (CCK-AR) and CCK-B receptors (CCK-BR), according to their affinity for the peptide agonists $\mathrm{CCK}$ and gastrin ${ }^{[2]}$. Our previous experiments demonstrated that $\mathrm{CCK}-8$, as an intestinal neuropeptide, not only protected gastric mucosa against alcohol-induced injury, but also was a potent protective agent against acute lung injury caused by lipopolysaccharide $(\mathrm{LPS})^{[3,4]}$. It reduced pulmonary artery hypertension
(PAH) and lessened inflammatory lesions in lung tissues of endotoxin shock (ES) rats ${ }^{[3,4]}$. Studies from our laboratory show that sulfated CCK-8 (sCCK-8) can inhibit LPS-induced TNF- $\alpha$ production in vitro, $\mathrm{sCD} 14$ release and $\mathrm{mCD} 14$ expression in rat pulmonary interstitial macrophages $(\mathrm{PIM})^{[5]}$. The production of proinflammatory cytokines, including TNF- $\alpha$, IL-1 $\beta$, and IL-6 in ES rats, was also inhibited by sCCK- 8 in vivo ${ }^{[6,7]}$. The above data suggest that $\mathrm{SCCK}-8$ has an antiinflammatory effect, confirmed by a morphological observation that sCCK-8 clearly lessened the inflammatory lesions in the spleen and the liver tissues in endotoxin shock rats ${ }^{[4]}$. However, the anti-inflammatory mechanisms and signaling pathways activated by CCK- 8 remain unclear.

Several signaling pathways are involved in the activa- 
tion of monocytes/macrophages induced by LPS, including the mitogen-activated protein kinase (MAPK) and the protein kinase $\mathrm{C}$ (PKC) pathway, and there is a lot of cross-talk between them. PKC, as an important message molecule, participates extensively in immune regulation and inflammatory signal transduction. In particular, $\mathrm{PKC} \zeta$ plays a pivotal role in the complicated signaling networks induced by LPS ${ }^{[8,9]}$. Several studies show that LPS-induced activation of the extracellular signal-regulated kinases (ERK) in alveolar macrophages is mediated by sequential activation of phosphatidylcholine-specific phospholipase C (PC-PLC), induction of cellular diacyglycerol (DAG) and ceramide, and activation of PKC $\zeta^{[10]}$. Previously we reported that CCK-AR and CCK-BR mRNA expressions were detected by reverse transcriptionpolymerase chain reaction. The presence of functional CCK receptors was confirmed by radioligand binding assay in rat PIM, and their expressions were upregulated by LPS ${ }^{[11]}$. Increasing evidence supports the concept that the signal transduction cascades mediated by CCK receptors are cell specific. For example, CCK was found to activate cAMP and PKC regulated signaling pathways in pancreatic acinar cells, but CCK-8 induced a significant decrease in membrane and cytosol PKC activity in murine lymphocytes, neutrophils, and peritoneal macrophages, as well as an increase of intracellular cAMP levels ${ }^{[12-14]}$. As PIM plays an important role in the inflammatory response to LPS in the lungs and little is known about the effect of CCK- 8 on DAG-PKC signaling pathway in PIM, the present study was undertaken to investigate the effect of CCK-8 on DAG contents, PKC activities, and PKC $\zeta$ translocation in resting and LPS-stimulated rat PIM, and to explore the anti-inflammatory molecular mechanisms activated by CCK-8.

\section{Materials and methods}

Chemicals and reagents Collagenase IA, LPS (Escherichia coli 0111:B4), CCK-8s, proglumide, CR-1409, CR-2945, aprotinin, leupeptin, and DNaseI were obtained from Sigma Chemical Co. RPMI-1640 culture medium, phenylmethylsulfonyl-fluoride (PMSF), and nitrocellulose membranes were obtained from Gibco BRL. DAG biotrak assay reagents system (RPN 200) and Amprep Si minicolumns (RPN 1906) were obtained from Amersham Biosciences. SignaTECT® PKC assay system and Gel shift assay system were obtained from Promega. Diethylaminoethyl cellulose (DE52) was obtained from Whatman BioSystems. Affinity purified polyclonal nPKC $\zeta$ antibodies (C-20), peroxidase-conjugated goat antirabbit IgG, and Western blotting luminol reagent (sc-2048) were obtained from Santa Cruz Biotechnology. All other reagents were of analytic pure grade.

Animals Adult healthy female Sprague-Dawley (SD) rats (180-220 g, Grade II, Certificate № 04057) were obtained from the Experimental Animal Center of Hebei Province (Shijiazhuang, China).

Cell culture and treatment PIM were isolated from perfused rat lungs with a collagenase digestion technique, modified as Wizemann et $a l^{[15]}$. PIM were harvested with PBS containing $0.4 \mathrm{~g} / \mathrm{L}$ edetic acid, pelleted by centrifugation $\left(4{ }^{\circ} \mathrm{C}, 400 \times g, 10 \mathrm{~min}\right)$ and resuspended with serum-free medium. Cells were incubated with CCK-8 at different concentrations or stimulated with LPS $(10 \mathrm{mg} / \mathrm{L})$ in the absence or presence ofCCK-8, proglumide, CR-1409, and CR-2945 for $1 \mathrm{~h}$. At the end of incubation, PIM were centrifuged at $400 \times g$ for $60 \mathrm{~s}$, and the pellets were measured for DAG contents, PKC activities, and translocation.

Measurement of intracellular DAG contents Total cell lipids were extracted using a modification of the method of Bligh and Dyer ${ }^{[16]}$. Intracellular DAG contents were measured using the DAG assay reagents system from Amersham Biosciences. A radioenzymatic assay uses the diacylglycerol kinase and defined mixed micelle conditions to solubilize the DAG present and allow its quantitative conversion to $\left[{ }^{32} \mathrm{P}\right]$ phosphatidic acid in the presence of $\left[\gamma-{ }^{32} \mathrm{P}\right]$ ATP. Following the enzyme-catalyzed phosphorylation of DAG, the $\left[{ }^{32} \mathrm{P}\right]$ phosphatidic acid reaction product was extracted and separated by Amprep chromatography. The radioactivity attributable to $\left[{ }^{32} \mathrm{P}\right]$ phosphatidic acid was determined by liquid scintillation counting. The amount of DAG present in the sample was calculated from the amount of $\left[{ }^{32} \mathrm{P}\right]$ phosphatidic acid produced and the specific activity of the ATP according to the standard curve was expressed as pmol per $2 \times 10^{6}$ cells.

Preparation of cytosol and membrane fractions After treatment, the PIM were washed with $5 \mathrm{~mL}$ ice-cold PBS and centrifuged at $250 \times g$ for $60 \mathrm{~s}$. The supernatant was discarded and the cells were suspended in iced $0.5 \mathrm{~mL}$ of extraction buffer [Tris-HCl $25 \mathrm{mmol} / \mathrm{L}$ ( $\mathrm{pH}$ 7.4) containing edetic acid $0.5 \mathrm{mmol} / \mathrm{L}$, egtazic acid $0.5 \mathrm{mmol} / \mathrm{L}, \beta$-mercaptoethanol $10 \mathrm{mmol} / \mathrm{L}$, leupeptin $1 \mathrm{mg} / \mathrm{L}$, and aprotinin $1 \mathrm{mg} / \mathrm{L}]$ and sonicated on ice with 10 -s bursts, each preceded by a 10 -s pause. The homogenates were centrifuged at $100000 \times g$ for $60 \mathrm{~min}$ at $4{ }^{\circ} \mathrm{C}$ and the supernatant was used for assay of PKC (cytosol fraction). The pellet (representing the membrane fraction) was suspended in $2 \mathrm{~mL}$ of iced extraction buffer containing $0.05 \%$ Triton $\mathrm{X}-100$, shaken for 60 min at $4{ }^{\circ} \mathrm{C}$ and centrifuged at $100000 \times g$ at $4{ }^{\circ} \mathrm{C}$ for $60 \mathrm{~min}$. The supernatant was taken for assay of PKC (membrane fraction). Cytosol and membrane fractions were partially purified 
using diethylaminoethyl (DEAE)-cellulose chromatography. The samples were passed over individual 1-mL columns preequilibrated with extraction buffer. Following washing the columns 1 time with $5 \mathrm{~mL}$ of extraction buffer, the fractions of PKC were eluted with $5 \mathrm{~mL}$ of extraction buffer containing $\mathrm{NaCl} 200 \mathrm{mmol} / \mathrm{L}$, stored at $4^{\circ} \mathrm{C}$, and generally assayed within $24 \mathrm{~h}$.

PKC activity assay PKC activity was analyzed by measuring the incorporation of ${ }^{32} \mathrm{P}$ from $\left[\gamma-{ }^{32} \mathrm{P}\right] \mathrm{ATP}(185 \mathrm{PBq} / \mathrm{mol})$ into peptide Neurogranin ( ${ }_{28} \mathrm{AAKIQAS} *$-FRGHMA-RKK $\left.{ }_{43}\right)$, a specific substrate of PKC. The standard assay mixture $(25 \mu \mathrm{L})$ contained extraction buffer $5 \mu \mathrm{L}, 5 \mu \mathrm{L}$ PKC co-activation buffer $(5 \times), 5 \mu \mathrm{L}$ PKC substrate peptide $0.5 \mathrm{mmol} / \mathrm{L}$, and $5 \mu \mathrm{L}$ of ATP mixture containing ATP $0.5 \mathrm{mmol} / \mathrm{L}$ and $\left[\gamma-{ }^{32} \mathrm{P}\right]$ ATP $18.5 \mathrm{GBq}(0.5 \mathrm{Ci})$. Control reaction used a control buffer instead of PKC substrate peptide. The reaction was terminated by adding ice-cold $7.5 \mathrm{~mol} / \mathrm{L}$ guanidine hydrochloride $12.5 \mu \mathrm{L}$ at $30{ }^{\circ} \mathrm{C}$ after $5 \mathrm{~min}$. Each terminated reaction mixture $(10 \mu \mathrm{L})$ was then spotted onto an SAM membrane. The membrane was rinsed with $2 \mathrm{~mol} / \mathrm{L} \mathrm{NaCl}$ and $2 \mathrm{~mol} / \mathrm{L} \mathrm{NaCl}$ in $1 \%$ phosphoric acid and deionized water, respectively. Aliquots of $5 \mu \mathrm{L}$ in any 2 reactions were spotted onto SAM membrane. All membranes were dried at room temperature and put into liquid scintillator. Radioactivity was counted. All values represented the mean from 3 separate culture dishes, with an average difference between duplicates of $< \pm 5 \%$. Proteins were measured using Bradford's method by using bovine serum albumin as a standard.

Immunoblot analysis The effect of CCK-8 on distribution and on LPS-induced translocation of $\mathrm{PKC} \zeta$ was determined using quantitative immunoblot analysis. Crude cytosolic and membranous fractions from PIM were prepared as described above, except that DE52 column chromatography was omitted. Protein concentrations of fraction were measured using Bradford's method using bovine serum albumin as standard. Aliquots of sample eluates were added to sample preparation buffer [Tris-HCl $0.05 \mathrm{~mol} / \mathrm{L}, \mathrm{pH}$ 6.8, 20\% glycerol, $2 \%$ sodium dodecylsulfate (SDS), edetic acid $5 \mathrm{mmol} / \mathrm{L}$, egtazic acid $5 \mathrm{mmol} / \mathrm{L}, \beta$-mercaptoethanol $10 \mathrm{mmol} / \mathrm{L}$, leupeptin $1 \mathrm{mg} / \mathrm{L}$, aprotinin $1 \mathrm{mg} / \mathrm{L}$, PMSF $0.5 \mathrm{mmol} / \mathrm{L}$, and $0.1 \%$ bromphenol blue] and boiled for $5 \mathrm{~min}$. The proteins were separated by SDS-polyacrylamide ( $10 \%$ acrylamide) gel electrophoresis and electrophoretically transferred to nitrocellulose membranes. The completeness of transfer was confirmed by staining the gel with Coomassie blue. The blots were incubated at room temperature for $2 \mathrm{~h}$ with PBS containing 5\% nonfat dry milk and $0.05 \%$ Tween 20 (bovine serum albumin/Tris buffer saline) to block non-specific sites. The blots were washed with PBS, and incubated overnight with affinity purified polyclonal $\mathrm{nPKC} \zeta$ antibodies(1:200) at $4{ }^{\circ} \mathrm{C}$. The blots were washed 3 times for $15 \mathrm{~min}$ each with PBS at room temperature and incubated at $37^{\circ} \mathrm{C}$ for $1 \mathrm{~h}$ with peroxidase-conjugated goat anti-rabbit IgG antibody. The blots were finally washed 3 times for 15 min each with Tris buffer saline, incubated with enhanced chemiluminescence detection reagents for 3-5 min and exposed to X-ray films for up to $60 \mathrm{~s}$. The density of the bands on the film was analyzed by Gel-Pro analyzer version 3.1 software (Media Cybernetics). The arbitrary unit $\left(D_{\text {area }} \cdot D_{\text {density }}\right)$ was used for expressing the relative level of PKC $\zeta$ of cytosolic and membranous fractions from PIM.

Statistical analysis Data were expressed as mean \pm SD and analyzed using analysis of variance and the least significant difference test using an SPSS statistical program. Statistical significance was accepted when $P<0.05$. Halfmaximal inhibition $\left(\mathrm{IC}_{50}\right)$ was calculated using the log-probit method.

\section{Results}

DAG content For resting PIM, CCK-8 did not affect DAG content at low concentrations $\left(1 \times 10^{-12}-1 \times 10^{-7} \mathrm{~mol} / \mathrm{L}, P>0.05\right)$, but decreased it at high concentrations $\left(1 \times 10^{-6}-1 \times 10^{-5} \mathrm{~mol} / \mathrm{L}\right)$ compared with that of the control group $(P<0.01)$. Stimulation of PIM by LPS $(10 \mathrm{mg} / \mathrm{L})$ obviously increased DAG content $(P<0.01)$ (Figure 1$)$. CCK-8 concentration-dependently inhibited the LPS-induced DAG content, and a significant inhibition was observed at high concentrations $\left(1 \times 10^{-8}-1 \times 10^{-5} \mathrm{~mol} / \mathrm{L}\right.$, $P<0.01)$, but not at low concentrations $\left(1 \times 10^{-11}-1 \times 10^{-9} \mathrm{~mol} / \mathrm{L}\right.$, $P>0.05$ ) (Figure 1). The inhibitory effect of CCK-8 on DAG content induced by LPS was abrogated in part by proglumide, CR-1409, and CR-2945 in a concentration-dependent manner. Proglumide was so potent that it had an obvious effect on CCK-8-resultant inhibition of LPS-induced DAG content increase at low concentrations, and even resulted in a full reversal of it at high concentrations, and a similar effect was found for CR-1409, but not for CR-2945, with CR-2945 showing a weak effect only at high concentrations. The $\mathrm{IC}_{50}$ of proglumide, CR-1409, andCR-2945 were $(1.76 \pm 0.19) \times 10^{-6} \mathrm{~mol} / \mathrm{L}$, $(6.76 \pm 0.52) \times 10^{-5} \mathrm{~mol} / \mathrm{L}$, and $(5.45 \pm 0.42) \times 10^{-3} \mathrm{~mol} / \mathrm{L}$, respectively (Figure 2).

PKC activity and translocation Treating resting PIM with CCK-8, no changes of cytosolic and membrane-bound PKC activities were found at low concentrations $\left(1 \times 10^{-12}\right.$ $1 \times 10^{-9} \mathrm{~mol} / \mathrm{L}$ ), but an increase of cytosolic PKC activities and a decrease of membrane-bound PKC activities were observed gradually with the increase of CCK- 8 concentration, and significant differences presented at $1 \times 10^{-6}-1 \times 10^{-5} \mathrm{~mol} / \mathrm{L}$ 


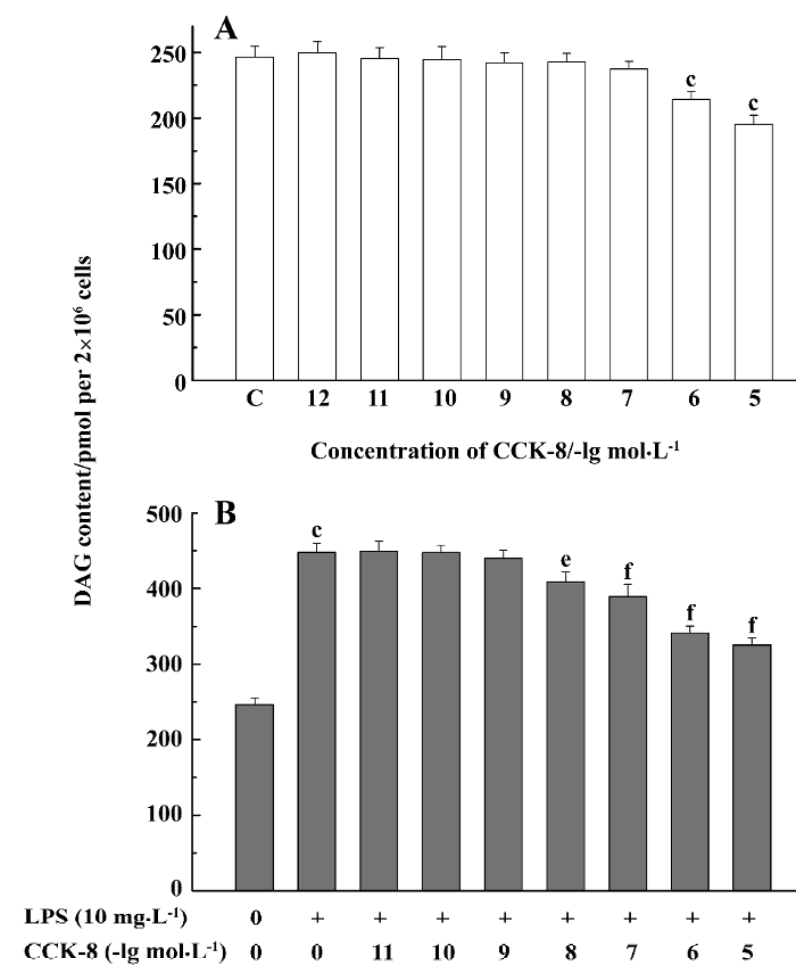

Figure 1. Effect of CCK-8 on DAG content in rat resting pulmonary interstitial macrophages (PIMs, A) and LPS-stimulated rat PIMs (B). PIMs were incubated with CCK-8 at different concentrations in the absence or presence of LPS for $1 \mathrm{~h}$. DAG content was determined by radioenzymatic assay. $n=3$. Mean \pm SD. ${ }^{\mathrm{c}} P<0.01 \mathrm{vs}$ control group. ${ }^{\mathrm{e}} P<0.05,{ }^{\mathrm{f}} P<0.01$ vs LPS group. C: control.

$(P<0.01)$ (Figure 3). LPS decreased cytosolic PKC activity and increased membrane-bound $\mathrm{PKC}$ activity $(P<0.01)$, indicating that LPS could promote PKC translocation and change its distribution, but did not affect its total activity in rat PIM. Treating PIM with CCK-8 did not affect LPS-induced PKC translocation at $1 \times 10^{-11}-1 \times 10^{-10} \mathrm{~mol} / \mathrm{L}$, decreased it slightly at $1 \times 10^{-9}-1 \times 10^{-8} \mathrm{~mol} / \mathrm{L}(P<0.05)$, and inhibited it significantly at $1 \times 10^{-7}-1 \times 10^{-5} \mathrm{~mol} / \mathrm{L}(P<0.01)$, suggesting that $\mathrm{CCK}-8$ inhibited LPS-induced PKC translocation in a concentrationdependent manner (Figure 3). The inhibitory effect of CCK-8 $1 \times 10^{-6} \mathrm{~mol} / \mathrm{L}$ on LPS-induced PKC activity translocation in rat PIM was attenuated by proglumide, CR-1409, and CR-2945 at $1 \times 10^{-4} \mathrm{~mol} / \mathrm{L}$, and their inverse rate (percentage of CCK-8) were $58.9 \%, 48.1 \%$, and $21.5 \%$, respectively $(P<0.01)$ (Figure 4).

Immunoblot analysis For resting PIM, CCK-8 inhibited $\mathrm{PKC} \zeta$ translocation from cytosol to membrane only at high concentrations $\left(1 \times 10^{-6} \mathrm{~mol} / \mathrm{L}\right)(P<0.05)$ (Figure 5). LPS promoted $\mathrm{PKC} \zeta$ translocation from cytosol to membrane $(P<$ $0.01)$ and CCK-8 inhibited LPS-induced PKC $\zeta$ translocation

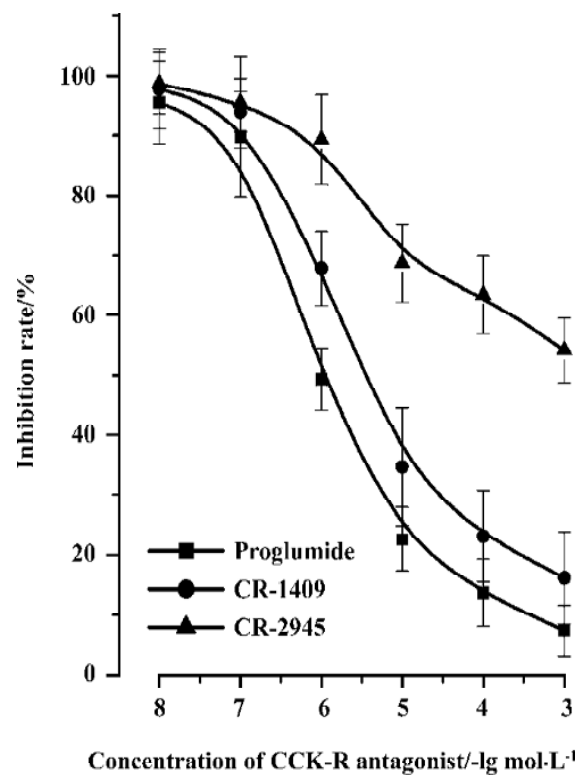

Figure 2. CCK-receptor non-selective and selective antagonists abrogated the inhibitory effects of CCK-8 on the increase in diacyglycerol (DAG) content induced y LPS. Pulmonary interstitial macrophages were isolated and pretreated with CCK receptor antagonists (proglumide, CR-1409, and CR-2945) for $10 \mathrm{~min}$ prior to addition of LPS $(10 \mathrm{mg} / \mathrm{L})$ and CCK $-8\left(1 \times 10^{-6} \mathrm{~mol} / \mathrm{L}\right)$, and then co-incubated for $1 \mathrm{~h}$. DAG content was determined by radioenzymatic assay. $n=3$. Mean $\pm \mathrm{SD}$.

significantly at $1 \times 10^{-8}$ and $1 \times 10^{-6} \mathrm{~mol} / \mathrm{L}(P<0.01$, Figure 6$)$. The inhibitory effect of CCK-8 on LPS-induced PKC $\zeta$ translocation was blocked by proglumide, CR-1409 $(P<0.01)$, and CR-2945 $(P<0.05)$ to some extent (Figure 7).

\section{Discussion}

CCK is a neuropeptide expressed in the endocrine I-cells of the small intestinal mucosa and in widespread central and peripheral neurons ${ }^{[17]}$. Whereas intestinal CCK regulates the release of pancreatic enzymes and the contraction of the gall bladder, neuronal CCK is a transmitter or modulator assumed to be involved in a variety of CNS functions, such as feeding behavior, anxiety, analgesia, memory, immunomodulation, and anti-opioid effects ${ }^{[1,18,19]}$. CCK receptor is a $G$ protein-coupled receptor with seven-transmembrane domain that has attracted considerable interest as a target for drug-discovery efforts, based on its important physiological role in the gastric mucosa, CNS, and immune cells $^{[20]}$. CCK acting through its $\mathrm{G}$ protein-coupled receptor is now known to activate a variety of intracellular signaling mechanisms and, thereby, to regulate a complex array of cellular functions in different types of cells. Data from several labs indicates that CCK increases intracellular calcium in 


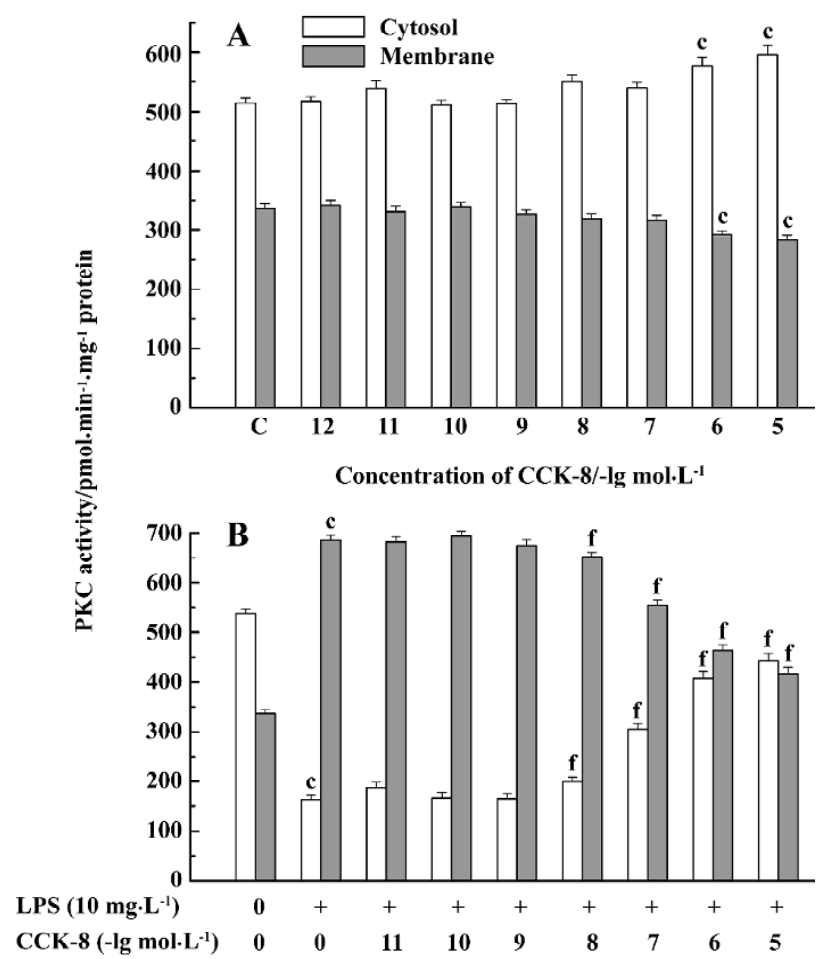

Figure 3. Effect of CCK-8 on protein kinase $\mathrm{C}$ translocation in rat resting pulmonary interstitial macrophages (PIMs, A) and LPS-stimulated rat PIMs (B). PIMs were incubated with CCK-8 at various concentrations in the absence or presence of LPS for $1 \mathrm{~h}$. PKC activities were determined by radioenzymatic assay. $n=3$. Mean \pm SD . ${ }^{\mathrm{c}} P<0.01$ vs control group. ${ }^{\mathrm{f}} P<0.01$ vs LPS group. C: control.

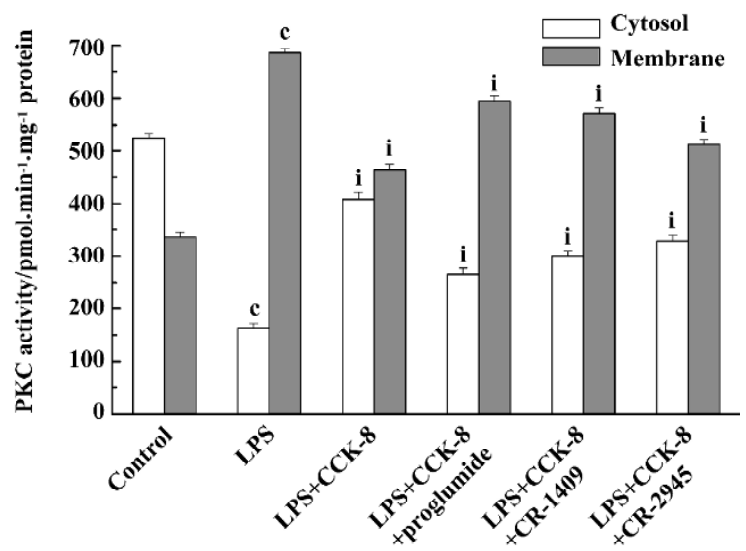

Figure 4. Effects of proglumide, CR-1409, and CR-2945 on LPSinduced protein kinase $\mathrm{C}$ translocation in rat pulmonary interstitial macrophages (PIMs). PIMs were isolated and pretreated with CCK receptor antagonists (proglumide, CR-1409, and CR-2945) for $10 \mathrm{~min}$ prior to addition of LPS $(10 \mathrm{mg} / \mathrm{L})$ and CCK- $8\left(1 \times 10^{-6} \mathrm{~mol} / \mathrm{L}\right)$, and then co-incubated for $1 \mathrm{~h}$. PKC activity was determined by radioenzymatic assay. $n=3$. Mean \pm SD. ${ }^{\circ} P<0.01 v s$ control group. ${ }^{\mathrm{f}} P<0.01$ vs LPS group. ${ }^{\mathrm{i}} P<0.01$ vs LPS + CCK-8 group.
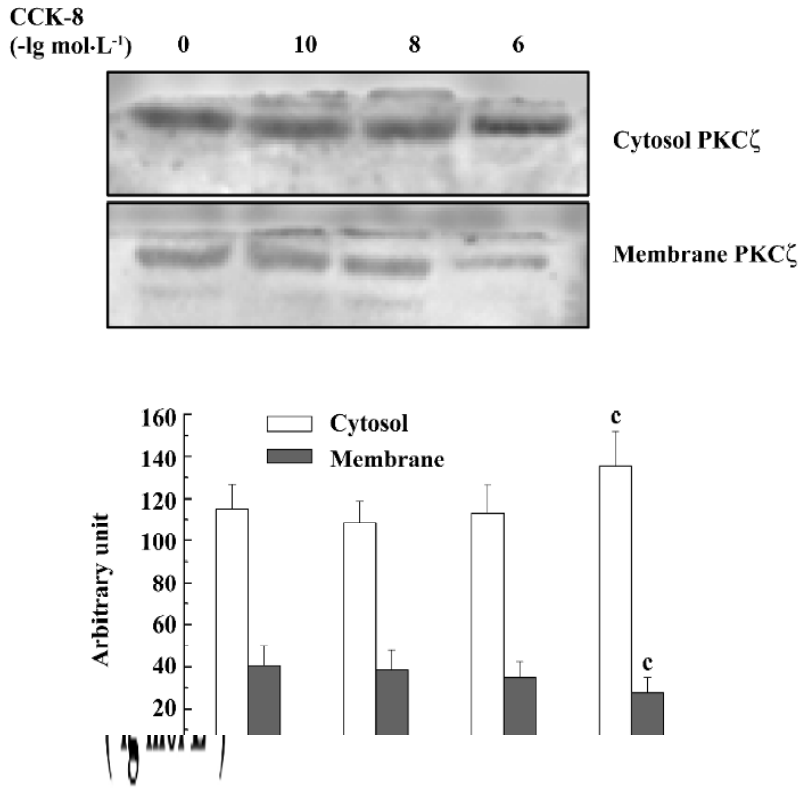

Figure 5. Effect of CCK-8 on $\mathrm{PKC} \zeta$ translocation in rat resting pulmonary interstitial macrophages. Upper: Representative immunoblot analysis. Lower: Relative protein levels of PKC $\zeta$ of 3 individual experiments. $n=3$. Mean \pm SD. ${ }^{c} P<0.01 v s$ control group.

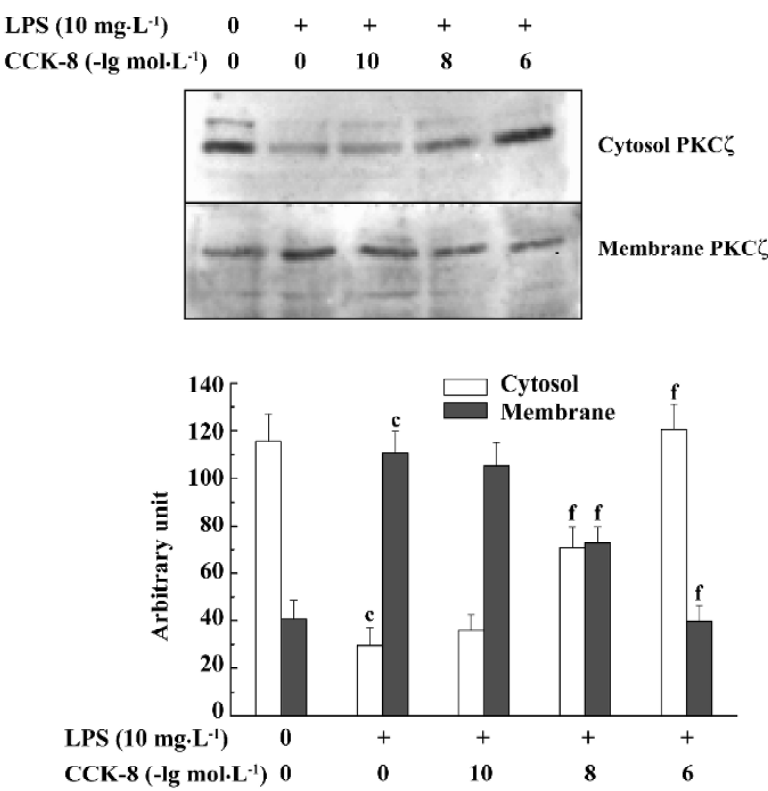

Figure 6. Effect of CCK-8 on LPS-induced PKC $\zeta$ translocation in rat PIMs. Upper: Representative immunoblot analysis. Lower: Relative protein levels of $\mathrm{PKC} \zeta$ of three individual experiments analyzed by Gel-pro analyzer software. $n=3$. Mean \pm SD. ${ }^{\mathrm{c}} P<0.01$ vs control group. ${ }^{\mathrm{f}} P<0.01$ vs LPS group. 

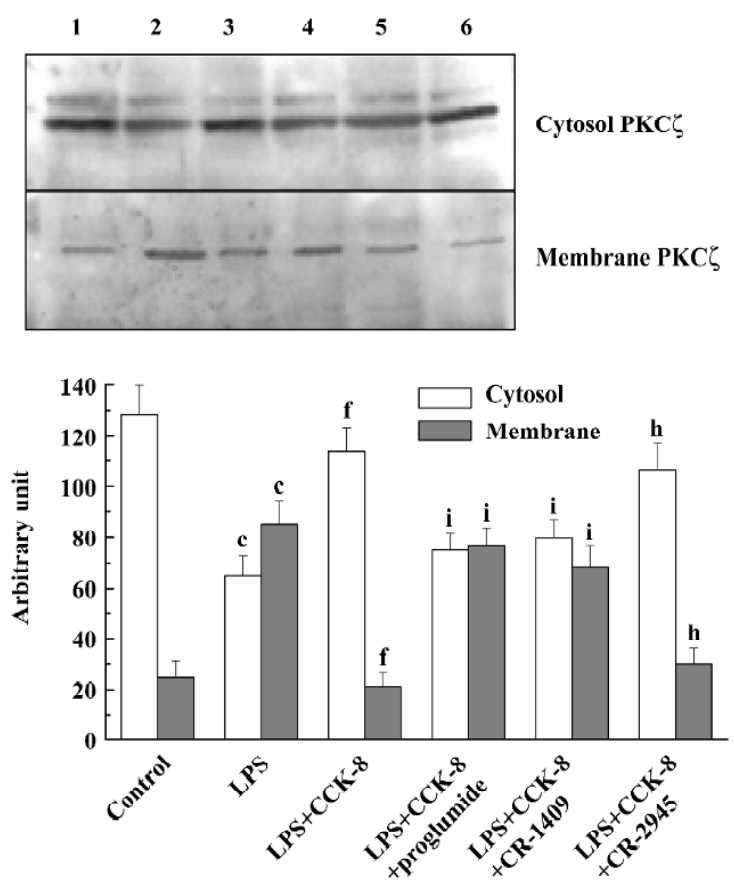

Figure 7. Effects of proglumide, CR-1409, and CR-2945 on LPSinduced $\mathrm{PKC} \zeta$ translocation in rat pulmonary interstitial macrophages. Upper: Representative immunoblot analysis. Lane 1, control; lane 2, LPS; lane 3, LPS+CCK-8 $1 \times 10^{-6} \mathrm{~mol} / \mathrm{L}$; lane 4 , LPS+CCK- $8+$ proglumide; lane 5, LPS+CCK-8+CR-1409; lane 6, LPS+CCK-8+CR-2945. Lower: Relative protein level of PKC $\zeta$ of three individual experiments analyzed by Gel-pro analyzer software. $n=3$. Mean \pm SD. ${ }^{c} P<0.01$ vs control group. ${ }^{\mathrm{f}} P<0.01 v s$ LPS group. ${ }^{\mathrm{h}} P<0.05,{ }^{\mathrm{i}} P<0.01 v s$ LPS $+\mathrm{CCK}-$ 8 group.

human peripheral blood mononuclear cells and T lymphocyte cell lines ${ }^{[21]}$. sCCK-8 can inhibit the mobility capacity and the mitogen-induced lymphocytic proliferation, but can increase the adherence and the spontaneouse proliferation of lymphocytes ${ }^{[22,23]}$. In addition, sCCK- 8 is a negative modulator of several functions of resting murine peritoneal macrophages and human neutrophils, including the production of superoxide anion, phagocytosis and mobility, and the inhibition of these activities is carried out through an increase of intracellular cAMP levels and a decrease in PKC activity $^{[11]}$. In the present study sCCK-8 did not affect DAG content, PKC activities, and PKC $\zeta$ translocation at low concentrations, but decreased DAG content and inhibited PKC activities and PKC $\zeta$ translocation at high concentrations in rat resting PIM. Resting PIM were not sensitive to the stimulation by sCCK-8, and CCK- 8 was a negative modulator of the DAG-PKC signaling pathway at physiological concentrations, which was very important for maintaining body homeostasis, and inhibited the DAG-PKC signaling pathway at high con-centrations.
LPS is the major component of the outer leaflet of Gramnegative bacteria and has profound immunostimulatory and inflammatory capacity. LPS interacts with LPS-binding protein, therefore allowing binding to CD14 and association with the Toll-like receptor $4(\mathrm{Tlr} 4)$ containing an intracellular signaling domain. Binding of LPS to these receptors results in the activation of several signaling cascades, such as PKC and $\mathrm{MAPK}^{[24]}$. PKC isoforms are involved in a wide variety of intracellular signaling events and play a significant role in many aspects of immune response, from development, differentiation, activation, and survival of lymphocytes to macrophage activation ${ }^{[25]}$. $\mathrm{PKC} \zeta$ is a member of the atypical subfamily and has been widely implicated in the regulation of cellular functions, particularly in the LPS-induced inflammatory response $\mathrm{e}^{[9]}$. In the present study, stimulation of PIM by LPS increased DAG content, promoted PKC activities and $\mathrm{PKC} \zeta$ translocation, and changed its distribution, but did not affect PKC total activity. In resting cells or in the absence of lipid hydrolysis, PKC are localized primarily to the cytosol. Translocation to the membrane from cytosol is an important step in PKC activation that can be initiated directly with phorbol esters or by receptor-stimulated increases in DAG. Activation of the enzyme might also be influenced by changes in membrane structure or constituents $^{[9]}$. Our results suggest that LPS could activate DAGPKC signaling pathway in rat PIM, which is in accordance with previous reports.

Macrophages stimulated by LPS or other inflammatory factors produce and release large quantities of various proinflammatory cytokines, including TNF- $\alpha$, IL-1 $\beta$, and IL-6. Overproduction of the cytokines can result in systemic inflammatory response syndrome, multiple organ dysfunction syndrome (MODS) and death. NF- $\kappa B$ plays a pivotal role in LPS-induced TNF- $\alpha$ and IL- $1 \beta$ gene expressions. The PKC signaling pathway is linked to the upstream regulation mechanism of NF- $\kappa \mathrm{B}$ activation. In particular, recent findings show that PKC $\zeta$ can regulate NF- $\kappa B$ through an I $\mathrm{BB}$ kinase (IKK)independent pathway, by directly phosphorylating $\operatorname{Ser}^{311}$ of the p65 subunit (RelA), and play an important role in mediating inflammatory response induced by LPS ${ }^{[26]}$. The present study showed that CCK-8 concentration-dependently inhibited LPS-induced DAG content, PKC activities, and PKC $\zeta$ translocation, and a significant inhibition was observed at high concentrations, but not at low concentrations. Cong et al reported that CCK-8 inhibited LPS-induced NF- $\kappa B$ binding activity in a concentration-dependent manner ${ }^{[21]}$. The present study demonstrated that CCK-8 significantly inhibited LPS-induced activation of the DAG-PKC signaling pathway at supraphysiological concentrations, which might be 
one of the upstream mechanisms for modulating NF- $\kappa B$ activity and exerting the anti-inflammatory effect of CCK-8.

However, it is unknown whether the inhibitory effect of CCK-8 on DAG-PKC signaling pathway induced by LPS was mediated through the CCK receptor or through which subtype of its receptor. Cong et al reported that CCK-8 inhibited NF- $\kappa \mathrm{B}$ binding activity and decreased I $\kappa \mathrm{B}-\alpha$ degradation through CCK receptors in rat PIM stimulated by $\operatorname{LPS}^{[21]}$. In the present study, the inhibitory effect of CCK-8 on LPSinduced DAG content, PKC activities and PKC $\zeta$ translocation was abrogated in part by proglumide, CR-1409, and CR2945 in a concentration-dependent manner. Proglumide was so potent that it had an obvious effect on CCK-8-resulted inhibition of LPS-induced DAG content, PKC activities, and $\mathrm{PKC} \zeta$ translocation at low concentrations, and even caused a full reversal of it at high concentrations. A similar effect was found for CR-1409, but not for CR-2945. CR-2945 showed a weak effect only at high concentrations. Our results indicate that the inhibitory effect of CCK- 8 on the LPS-activated DAG-PKC signaling pathway in rat PIM was mediated through the CCK receptor, and that both CCK-AR and CCKBR might be involved in this pathway. However, CCK-AR might play a major role in this process, which would be of benefit in the development of receptor-specific drugs in clinics.

In conclusion, CCK-8 was a negative modulator of the DAG-PKC signaling pathway in rat resting PIM, which was very important for maintaining body homeostasis, and significantly inhibited LPS-induced DAG content, PKC activity, and $\mathrm{PKC} \zeta$ translocation in a concentration-dependent manner. CCK receptors, particularly CCK-AR, might play a major role in this process. Inhibitory effects of CCK-8 on LPS-induced activation of the DAG-PKC signaling pathway might be one of the upstream mechanisms for modulating NF- $\kappa B$ activity and exerting its anti-inflammatory effect in rat PIM.

\section{References}

1 Crawley JN, Corwin RL. Biological actions of cholecystokinin. Peptides 1994; 15: 731-55.

2 Wank SA. Cholecystokinin receptors. Am J Physiol 1995; 269: G628-46.

3 Cong B, Li SJ, Ling YL, Yao YX, Gu ZY, Wang JX, et al. Expression and cell-specific localization of cholecystokinin receptors in rat lung. World J Gastroenterol 2003; 9: 1273-7.

4 Ling YL, Huang SS, Wang LF, Zhang JL, Wan M, Hao RL. Cholecystokinin octapeptide reverses experimental endotoxin shock. Acta Physiol Sin 1996; 48: 390-4.

5 Li SJ, Cong B, Yan YL, Yao YX, Ma CL, Ling YL. Cholecystokinin octapeptide inhibits the in vitro expression of CD14 in rat pulmonary interstitial macrophage induced by lipopolysaccharide.
Chin Med J 2002; 115: 276-9

6 Ling YL, Meng AH, Zhao XY, Shan BE, Zhang JL, Zhang XP. Effect of cholecystokinin on cytokines during endotoxic shock in rats. World J Gastroenterol 2001; 7: 667-71.

7 Meng AH, Ling YL, Zhang XP, Zhao XY, Zhang JL. CCK-8 inhibits expression of TNF- $\alpha$ in the spleen of endotoxic shock rats and signal transduction mechanism of p38 MAPK. World J Gastroenterol 2002; 8: 139-43.

8 Tan SL, Parker PJ. Emerging and diverse roles of protein kinase $\mathrm{C}$ in immune cell signaling. Biochem J 2003; 376: 545-52.

9 Hiral T, Chida K. Protein kinase $\mathrm{C} \zeta$ (PKC $\zeta$ ): activation mechanisms and cellular functions. J Biochem 2003; 133: 1-7.

10 Monick MM, Carter AB, Gudmundsson G, Mallampalli R, Powers LS, Hunninghake GW. A phosphatidylcholine-specific phospholipase $\mathrm{C}$ regulates activation of $\mathrm{p} 42 / 44$ mitogen-activated protein kinases in lipopolysaccharide-stimulated human alveolar macrophages. J Immunol 1999; 162: 3005-12.

11 Xu SJ, Gao WJ, Cong B, Yao YX, Gu ZY. Effect of lipopolysaccharide on expression and characterization of cholecystokinin receptors in rat pulmonary interstitial macrophages. Acta Pharmacol Sin 2004; 25: 1347-53.

12 De la Fuente M, Campos M, Del Rio M. Inhibition of murine peritoneal macrophage functions by sulfated cholecystokinin octapeptide. Regul Pept 1995; 55: 47-56.

13 Carrasco M, Del Rio M, Hernanz A. Inhibition of human neutrophil functions by sulfated and nonsulfated cholecystokinin octapeptides. Peptides 1997; 18: 415-22.

14 Carrasco M, Hernanz A, De La Fuente M. Effect of cholecystokinin and gastrin on human peripheral blood lymphocyte functions, implication of cyclic AMP and interleukin 2. Regul Pept 1997; 70: 135-42.

15 Wizemann TM, Laskin DL. Enhanced phagocytosis, chemotaxis, and production of reactive oxygen intermediates by interstitial macrophages following acute endotoxemia. Am J Respir Cell Mol Biol 1994; 11: 358-65.

16 Bligh EG, Dyer WJ. A rapid method of total lipid extraction and purification. Can J Biochem Physiol 1969; 37: 911-7.

17 Hansen TO. Cholecystokinin gene transcription: promoter elements, transcription factors and signaling pathways. Peptides 2001; 22: 1201-11.

18 Yang CX, Xu MY, Liu FY, Yang DX, Wang SZ. L-365, 260 reversed effect of sincalide against morphine on electrical and mechanical activities of rat duodenum in vitro. Acta Pharmacol Sin 2002; 23: 582-6.

19 Xu MY, Yang XP, Jin HB, Yang CX, Yang LZ. Devazcpide reversed effect of sincalide against morphine on rat jejunal activities. Acta Pharmacol Sin 1999; 20: 419-22.

20 Kopin AS, McBride EW, Schaffer K, Beinborn M. CCK receptor polymorphisms: an illustration of emerging themes in pharmacogenomics. Trends Pharmcol Sci 2000; 21:346-53.

21 Cong B, Li SJ, Yao YX, Zhu GJ, Ling YL. Effect of cholecystokinin octapeptide on tumor necrosis factor $\alpha$ transcription and nuclear factor- $\mathrm{KB}$ activity induced by lipopolysaccharide in rat pulmonary interstitial macrophages. World J Gastroenterol 2002; 8: 718-23.

22 Medina S, Rio MD, Cuadra BD, Guayerbas N, Fuente MD. Agerelated changes in the modulatory action of gastrin-releasing peptide, neuropeptide $\mathrm{Y}$ and sulfated cholecystokinin octapep- 
tide in the proliferation of murine lymphocytes. Neuropeptides 1999; 33: 173-9.

23 De la Fuente M, Carrasco M, Del Rio M, Hernanz A. Modulation of murine lymphocyte functions by sulfated cholecystokinin octapeptide. Neuropeptides 1998; 32: 225-33.

24 Monica C, Jordi X, Annabel FV, Carlos LL, Daniel JP, Antonio C. $\mathrm{PKC} \varepsilon$ is involved in JNK activation that mediates LPS-induced
TNF- $\alpha$, which induces apoptosis in macrophages. Am J Physiol Cell Physiol 2003; 285: C1235-45.

25 Tan SL, Parker PJ. Emerging and diverse roles of protein kinase $\mathrm{C}$ in immune cell signaling. Biochem J 2003; 376: 545-52.

26 Duran A, Diaz-Meco MT, Moscat J. Essential role of RelA Ser ${ }^{311}$ phosphorylation by $\zeta \mathrm{PKC}$ in NF- $\mathrm{KB}$ transcriptional activation. EMBO J 2003; 22: 3910-8.

\title{
The 3rd Singapore International Neuroscience Conference (SINC)
}

\author{
2006, May 23-24, Singapore
}

The NNI Conference Secretariat 3rdSINC 2006

National Neuroscience Institute

11 Jalan Tan Tock Seng

Singapore 308433

Phn:65-6357-7538/7152

Fax:65-6256-4755

E-mail:nni_secretariat@nni.com.sg

Http://www.nni.com.sg 